\title{
Enhancing load frequency control of multi-area multi-sources power system with renewable units and including nonlinearities
}

\author{
Mohamed Abdul Raouf Shafei ${ }^{1}$, Ahmed Nabil Abd Alzaher ${ }^{2}$, Doaa Khalil Ibrahim ${ }^{3}$ \\ ${ }^{1,3}$ Electrical Power Engineering Department, Faculty of Engineering, Cairo University, Egypt \\ ${ }^{2}$ Cairo Electricity Production Company, Egypt
}

\begin{tabular}{l} 
Article Info \\
\hline Article history: \\
Received Oct 8, 2019 \\
Revised Dec 22, 2019 \\
Accepted Jan 14, 2020 \\
\hline
\end{tabular}

Keywords:

Area control error (ACE)

Generation rate constraint

(GRC)

Governor dead band (GDB)

Integral time multiplied

absolute error (ITAE)

Load frequency control (LFC)

PID-P controller

\begin{abstract}
The foremost aims of the Load Frequency Control (LFC) is to maintain the frequency at nominal value and minimize the unscheduled tie line power flow between different control areas. The penetration of renewable energy sources into the grid is a recent challenge to the power system operators due to their different modelling rather than conventional units. In this paper, enhancing load frequency control of multi-area multi-sources power system with nonlinearities including renewable units is proposed using a new application of proportional-integral-derivative controller with proportional controller in the inner feedback loop, which is called as PID-P controller. To investigate the performance of the proposed controller, a thermal with reheater, hydro, wind and diesel power generation units with physical constraints such as governor dead band, generation rate constraint, time delay and boiler dynamics are considered. The proposed controller parameters are optimized using different heuristic optimization techniques such: Linearized Biogeography-Based Optimization technique, Biogeography-Based Optimization technique and Genetic Algorithm. The ability of the system to handle the large variation in load conditions, time delay, participation factors, and system parameters has been verified comprehensively.
\end{abstract}

\section{Corresponding Author:}

Mohamed Abdul Raouf Shafei,

Electrical Power Engineering Department,

Faculty of Engineering, Cairo University, Egypt.

Email: mohamed.shafei@eng.cu.edu.eg

\section{INTRODUCTION}

LFC is established to act during small and slow changes in real power and frequency. In a controllable area, LFC monitors the system frequency and tie-line power flows, computes the total change in the required generation (referred to area control error ACE) and changes the set point of the generation units within the area to save the average time of the ACE at a small value. Therefore, ACE, which reflects the integration of power net-interchange and frequency deviation, is considered as the controlled output of LFC, as both tie-line power and frequency errors will be enforced to zero when the ACE is driven to zero by the action of LFC [1].

Generally, numerous studies [2-9] have been carried out to improve the performance of LFC schemes; starting from classical control systems to modern control theories. It was deduced that most of the conventional controllers perform adequately at an operating point at which the controllers are designed but their performance may be dramatically changed when there is a large change in the operating point or system parameters [10]. Thus, hybrid control structure can be regarded as one of the most promising solutions to solve such limitations as deduced in [11-13]. 
Many researchers have concluded that fuzzy logic controller as mentioned in can improve the closed loop performance of I/PI/PID controllers and handle any changes in operating point or in system parameters by online updating of the controller parameters [14]. In [15], the frequency stability of power systems has been improved by the participation of high-penetration of wind power in grid frequency control, with the account in mind the both area are identical and the nonlinearities has been neglegted. Moreover, it is also observed from different research studies that the performance of the power system does not only depend on the artificial techniques employed but also on the controller structure and objective fitness function.

Recently, with the global trend toward the renewable resources, and with the ascending level of renewable energy units penetration into the grid, new research area is raised to test the performance of the different LFC schemes against different participation factors and system parameters. Therefore, authors believe that there is still much room for developing efficient LFC schemes. Thus, the main contribution of this paper is to validate the superiority of PID-P controller as a new application in the field of load frequency control of multi-area multi-sources power system in presence of both conventional and renewable units with taking into consideration the physical constraints and nonlinearities.

The controller parameters have been optimized using several recent optimization algorithms: Genetic Algorithm (GA), Biogeography-Based Optimization (BBO) and Linearized Biogeography-Based Optimization technique (LBBO) techniques while the integral time multiplied absolute error (ITAE) is the objective function. To examine the roubstness of the proposed controller, a thermal with reheater, hydro, wind and diesel power generation units with physical constraints such as governor dead band (GDB), generation rate constraint (GRC), time delay and boiler dynamics are considered. System modeling is developed in MATLAB/SIMULINK environment.

\section{RESEARCH METHOD}

As a matter of fact, PID controller is widely used due to its simplicity and robustness. On the other hand, it is inherently difficult to control the integrating process within it efficiently [16]. In [17], a PID-P controller has been proposed to overcome the structural limitation of PID controller in controlling integrating and unstable process. The structure of PID-P controller is illustrated in [10]. For such structure, an inner feedback loop with P controller is used to convert the unstable open loop or integrating process to open loop stable process, and then the PID controller can control the overall open loop stable process.

To validate the capabilities of the optimized PID-P controller, two unequal areas with conventional and renewable units including nonlinearities are considered as shown in Figure 1. Area-1 consists of reheat thermal, hydro and wind power plants while area- 2 consists of reheat thermal, hydro and diesel power plants. In the following, all symbols and parameters of such tested power system are defined, while the assigned values for system parameters are given in Appendix.

\begin{tabular}{|c|c|c|c|}
\hline$i$ & Area notation and takes 1 or 2 . & $U_{T H}$ & Control output of thermal unit. \\
\hline $\boldsymbol{B}_{\boldsymbol{i}}$ & Frequency bias constant. & $U_{H Y}$ & Control output of hydro unit. \\
\hline $\boldsymbol{R}_{\boldsymbol{i}}$ & $\begin{array}{l}\text { Governor speed regulation parameter of } \\
\text { area } i(\mathrm{~Hz} / \mathrm{p} . \mathrm{u} \mathrm{MW}) \text {. }\end{array}$ & $\boldsymbol{U}_{W}$ & Control output of wind unit. \\
\hline$T_{g i}$ & Speed governor time constant (sec). & $\boldsymbol{U}_{\boldsymbol{D}}$ & Control output of diesel unit. \\
\hline$\Delta \boldsymbol{F}_{\boldsymbol{i}}$ & Frequency deviation $(\mathrm{Hz})$. & $T_{12}$ & Synchronizing coefficient. \\
\hline$T_{p s i}$ & Power system time constant (sec). & $\boldsymbol{K}_{r}$ & Steam turbine reheat constant. \\
\hline$K_{p s i}$ & Power system gain. & $T_{r}$ & Steam turbine reheat time constant $(\mathrm{sec})$. \\
\hline$\Delta \boldsymbol{P}_{D i}$ & Load demand change (p.u). & $\boldsymbol{T}_{W}$ & $\begin{array}{l}\text { Normal starting time of water in penstock } \\
(\mathrm{sec}) \text {. }\end{array}$ \\
\hline$A C E_{i}$ & Area control error. & $T_{R S}$ & $\begin{array}{l}\text { Hydro turbine speed governor reset time } \\
(\mathrm{sec}) \text {. }\end{array}$ \\
\hline$T_{t i}$ & Turbine time constant (sec). & $T_{R H}$ & $\begin{array}{l}\text { Hydro turbine speed governor transient } \\
\text { droop time constant }(\mathrm{sec}) \text {. }\end{array}$ \\
\hline$\Delta \boldsymbol{P}_{\text {tie }}$ & Change in tie line power flow (p.u). & $T_{G H}$ & $\begin{array}{l}\text { Hydro turbine speed governor main servo } \\
\text { time constant }(\mathrm{sec}) \text {. }\end{array}$ \\
\hline
\end{tabular}




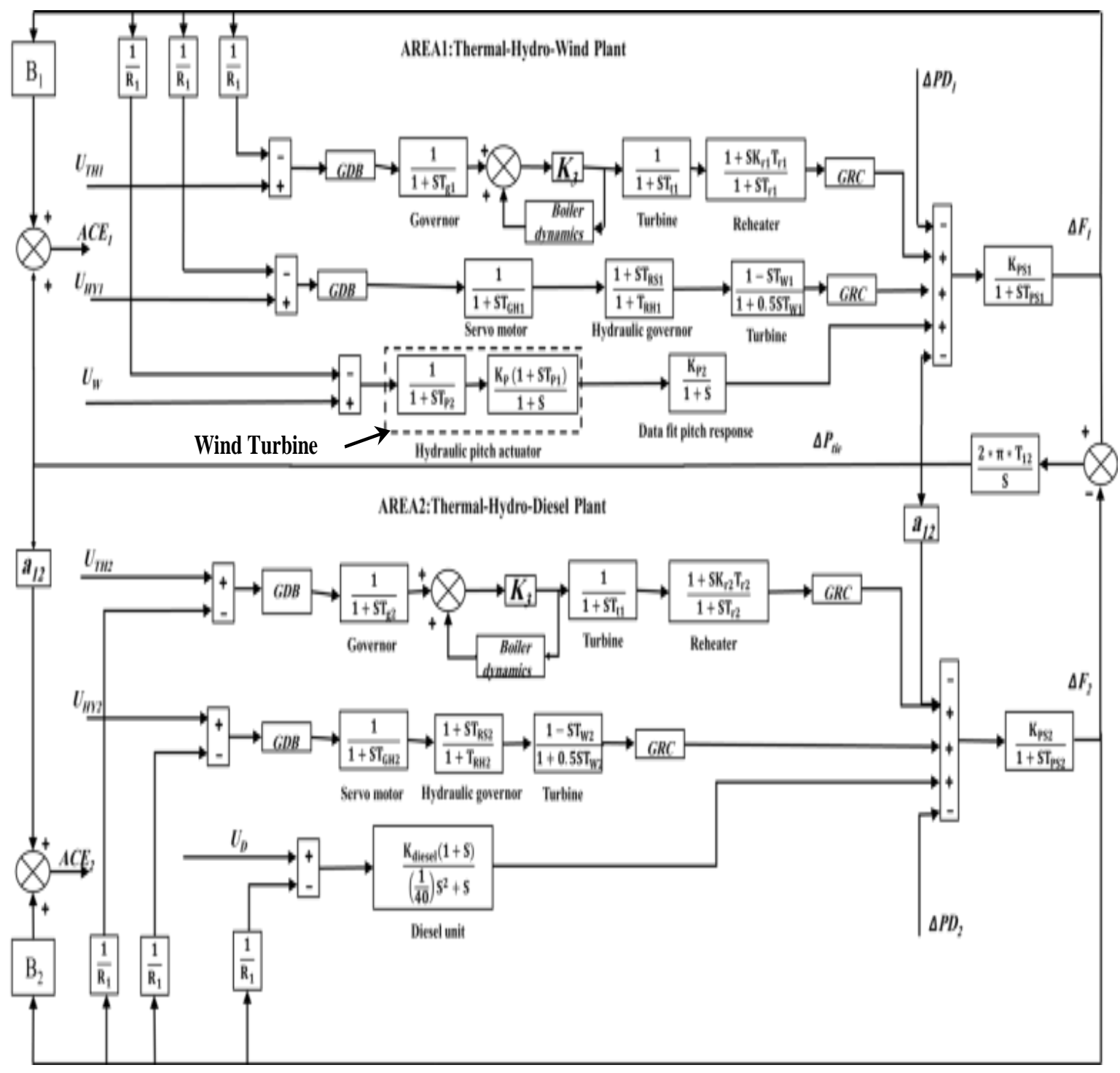

Figure 1. Transfer function model of multi-area multi-source power system with nonlinearities

The constraints that affect the power system performance such as generation rate constraint (GRC), governor dead band (GDB) and time delay are also included. Besides, boiler dynamics configuration is considered in thermal plants to generate steam under pressure where changes in the steam flow and deviations in pressure are sensed and the turbine control valves and boiler control introduce the resultant action. Furthermore, reheat turbine is included in this study as an effective nonlinearity. The block diagram of boiler dynamics configurations is illustrated in Figure 2 [18]. The assigned values for boiler dynamics parameters are shown in Appendix. 


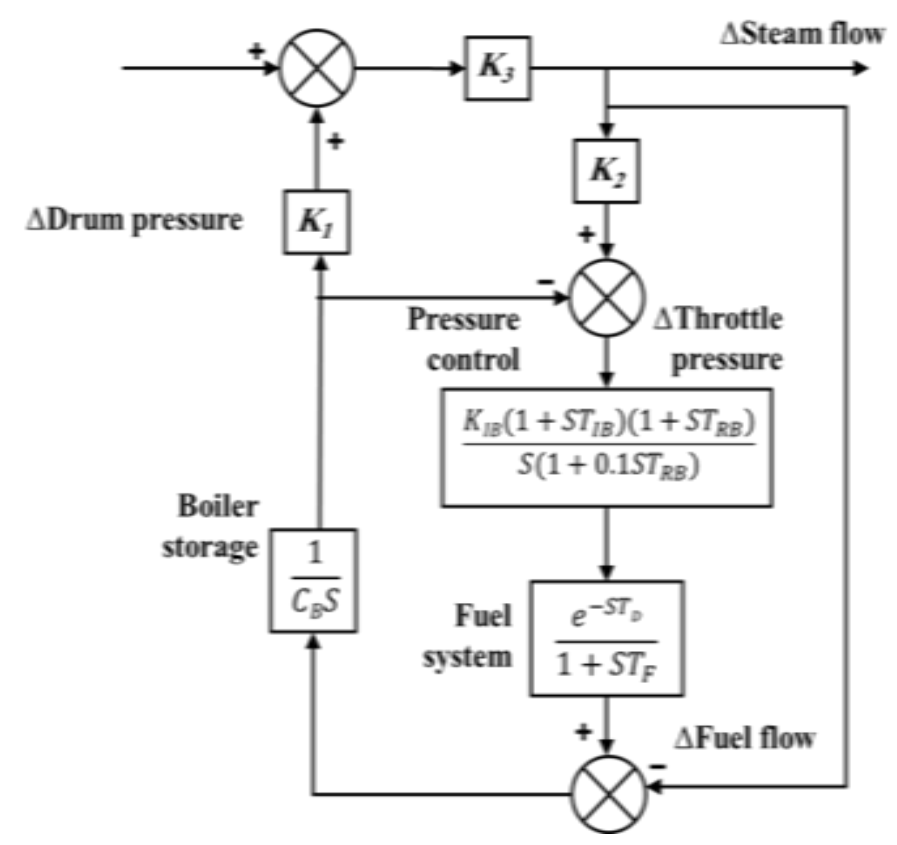

Figure 2. Transfer function model of boiler dynamics

It is worth mentioning that most of the published research studies didn't take into consideration the impact of all physical constraints and nonlinearities mentioned before. For example, in [19, 20] the effect of delay time in the system performance has been neglected, while in [21], the physical constraints and nonlinearities have been completely ignored. In [22], only reheat turbine as nonlinearity has been included. In [23], only GRC as a physical constraint has been considered while in [12], the effect of GRC and GDB has been investigated. In [24], the effect of reheat turbine, GRC and delay time has been studied without consideration of other nonlinearities and physical constraints. It is worthy to say that combining of all aforementioned physical constraints and nonlinearities may be considered a new area of research bearing in mind renewable energy resources.

It is noteworthy that the participation factors for different plants are assumed as in [18]. So, factors of 0.575 and 0.3 are assigned to thermal and hydro plants respectively while a factor of 0.125 is considered for both wind and diesel units. In the present investigation, a dead band nonlinearity of $0.05 \%$ is considered for the thermal plant and $0.02 \%$ for the hydro plant. A GRC of $3 \%$ per minute is considered for thermal units while considering $270 \%$ per minute for the hydro unit to raising generation and $360 \%$ per minute to lowering generation [18]. As well, to measure the reliability, efficiency, and robustness of the optimized PID-P controller implemented in the LFC scheme of the proposed power system, five test procedures are applied.

\section{PERFORMANCE EVALUATION}

\subsection{First Test Procedure: 1\% Step Load Increase in Area-1}

To investigate the dynamic performance of the selected controller, a step load increase of $1 \%$ is applied in area-1. The controller parameters are optimized using GA, BBO and LBBO as optimization techniques and (ITAE) as an objective function as discussed before. The obtained controller parameters $\left(K_{P 1}, K_{i}, K_{d}, K_{P 2}\right)$ for the three optimization techniques are shown in Table 1 . The system dynamic responses for the optimized PID-P controller for the two areas are shown in Figure 3. It is observed that the LBBO tuned PID-P controller has the least settling time while the BBO tuned PID-P controller has the least overshoot where the absolute value of the peak is considered as an overshoot in this study regardless of its direction (overshoot or undershoot). 
Table 1. Optimized parameters of PID-P controllers

\begin{tabular}{|c|c|c|c|c|c|c|c|c|c|}
\hline \multicolumn{10}{|c|}{ Controller Parameters of Optimized PID-P for Area-1 } \\
\hline & \multicolumn{3}{|c|}{ Thermal unit } & \multicolumn{3}{|c|}{ Hydro unit } & \multicolumn{3}{|c|}{ Wind unit } \\
\hline & GA & $\mathrm{BBO}$ & LBBO & GA & $\mathrm{BBO}$ & $\mathrm{LBBO}$ & GA & $\mathrm{BBO}$ & LBBO \\
\hline$K_{P 1}$ & 6.6055 & 0.0393 & 8.7836 & 1.7881 & 3.6204 & 6.5792 & 4.8085 & 25.2475 & 7.9714 \\
\hline$K_{i}$ & 2.2142 & 4.7151 & 2.7111 & 1.7206 & 21.1854 & 0.5958 & 8.9051 & 7.3818 & 14.5213 \\
\hline$K_{d}$ & 3.7526 & 19.7084 & 0.452 & 2.9945 & 17.7429 & 2.1061 & 2.457 & 8.0561 & 3.1253 \\
\hline$K_{P 2}$ & 1.4203 & 0.632 & 9.5214 & 2.2657 & 25.7295 & 6.3599 & 0.4899 & 9.8763 & 1.8951 \\
\hline \multicolumn{10}{|c|}{ Controller Parameters of Optimized PID-P for Area-2 } \\
\hline$K_{P 1}$ & 1.4828 & 1.242 & 6.7454 & 1.8259 & 0.2568 & 13.254 & 6.1326 & 16.585 & 1.8852 \\
\hline$K_{i}$ & 2.2934 & 0.3294 & 13.9548 & 4.1141 & 7.5174 & 1.4632 & 1.885 & 19.6848 & 0 \\
\hline$K_{d}$ & 4.9281 & 14.3159 & 4.5611 & 1.9045 & 23.55 & 1.3941 & 0.27098 & 22.5798 & 0.17 \\
\hline$K_{P 2}$ & 1.6191 & 27.9625 & 4.5 & 1.1218 & 0.4567 & 0.669 & 2.9666 & 12.1444 & 2.0851 \\
\hline
\end{tabular}

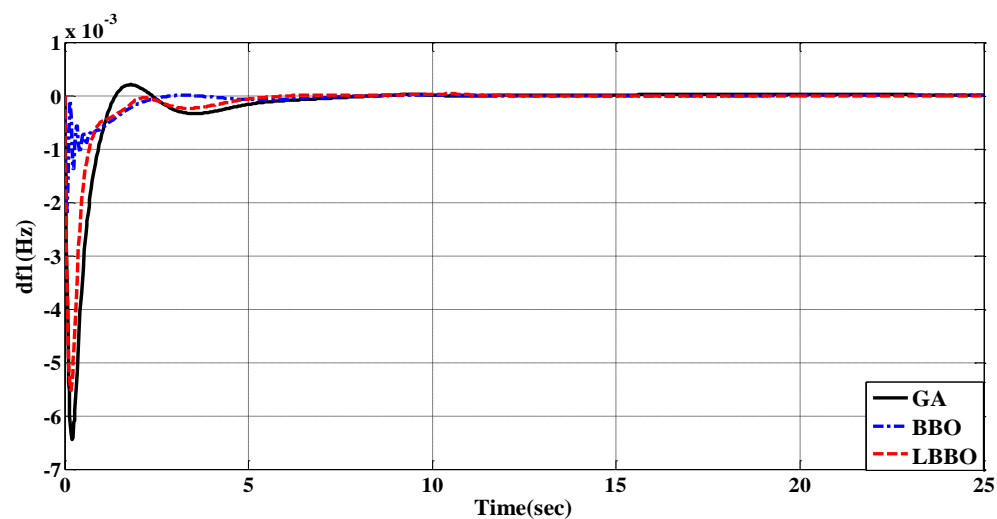

(a)

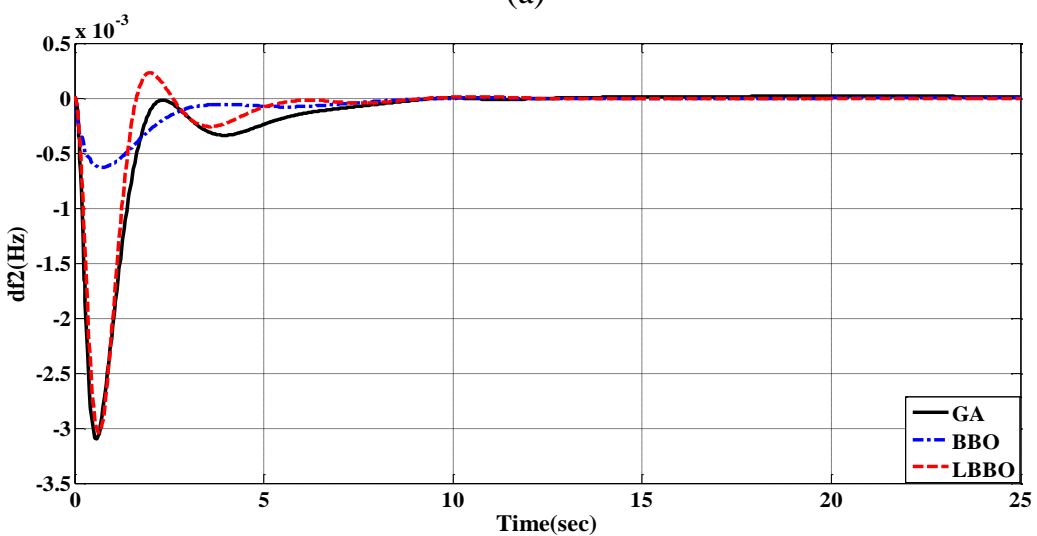

(b)

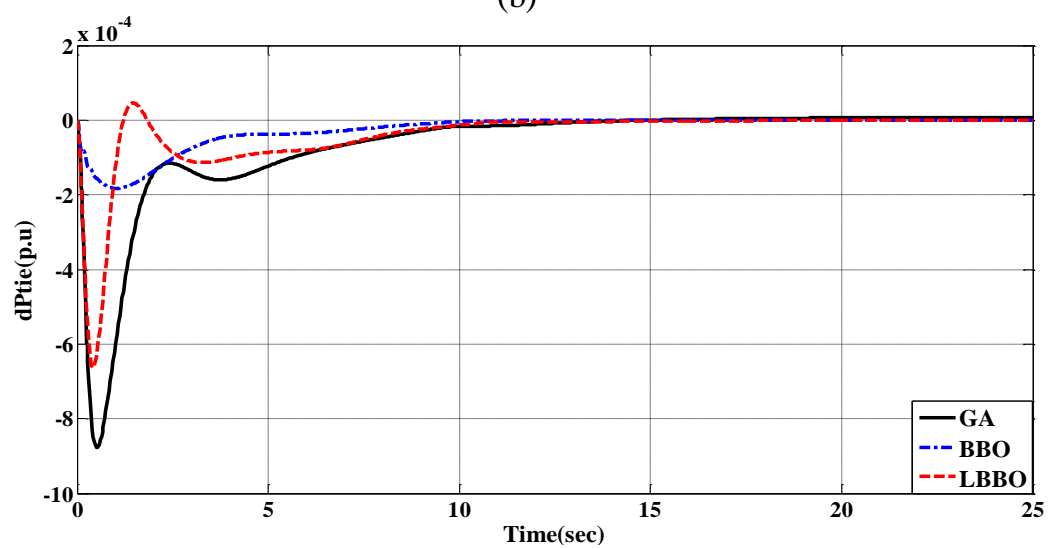

(c)

Figure 3. Test system performance for $1 \%$ step load increase in area-1, (a) Change in frequency of area-1, (b) Change in frequency of area-2, (c) Change in tie line power 
In addition, the achieved results are compared with some recently published studies in [18, 19] for the same power system as tabulated in Table 2. Such studies have tested some controllers tuned using Teaching Learning Based Optimization algorithm (TLBO) and Differential Evolution (DE). It is clear that the proposed optimized PID-P controller accomplishes better dynamic response with lesser settling time as compared to some other controllers.

Table 2. Comparative study for applying 1\% step load increase in area-1

\begin{tabular}{ccccccc}
\hline Controllers & \multicolumn{3}{c}{ Settling time $(2 \%$ band)(sec) } & \multicolumn{3}{c}{ Peak overshoot (p.u) } \\
& $\Delta F_{1}$ & $\Delta F_{2}$ & $\Delta P_{\text {tie }}$ & $\Delta F_{1}$ & $\Delta F_{2}$ & $\Delta P_{\text {tie }}$ \\
\hline DE tuned PID [18] & 19.68 & 21.93 & 25.89 & - & - & - \\
TLBO tuned PID [17] & 18.22 & 18.88 & 16.28 & - & - & - \\
TLBO tuned IDD [17] & 17.95 & 18.72 & 13.01 & - & - & - \\
TLBO tuned PIDD [17] & 16.14 & 16.79 & 12.77 & - & - & 0.0008 \\
GA tuned PID-P & 5.58 & 8.09 & 9.84 & 0.0065 & 0.0031 & 0.0001 \\
BBO tuned PID-P & 5.04 & 7.04 & 9.08 & 0.0022 & 0.0006 & 0.0006 \\
LBBO tuned PID-P & 4.54 & 5.17 & 9.7 & 0.0055 & 0.003 & - \\
\hline
\end{tabular}

\subsection{Second Test Procedure: $30 \%$ Step Load Increase in Both Areas}

A very large step load increase of $30 \%$ in both areas is applied to confirm the superiority of PID-P controller to wide change in operating conditions. Figure 4 depicts the performance dynamics of PID-P controllers without re-tuning the controllers' parameters. Table 3 provides a rich comparative study for the optimized PID-P controller using the three implemented optimization techniques. Based on the achieved results of Table 3, it is clear that the tested system has stable performance wherever the location and size of the disturbance change. Also, it can be deduced that the LBBO optimized PID-P controller has the best settling time while BBO optimized PID-P controller has the best overshoot.

\subsection{Third Test Procedure: Sensitivity Analysis}

The sensitivity analysis is carried out to investigate the ability of the controller to handle wide changes in operating conditions and system parameters without retuning the controller parameters. Taking one at a time, the operating load conditions, GRC, $T_{R H}, T_{G H}, T_{R S}, T_{T}$ and $R$ vary with $\pm 25 \%$ from their nominal values. It is observed that, the system is stable in all cases and the effect of the variation in operating loading conditions and system time constants on the system performance can be neglected. For GA tuned PID-P controller, the maximum increasing in settling time is $0.92 \mathrm{sec}$ for $25 \%$ increasing in GRC while for BBO tuned PID-P is $1.3 \mathrm{sec}$ for $25 \%$ decreasing in GRC. For LBBO tuned PID-P controller, the corresponding maximum increasing in settling time is $2.59 \mathrm{sec}$ for $25 \%$ decreasing in droop characteristic R.

\subsection{Fourth Test Procedure: Changing Participation Factors' Values}

The performance of PID-P controller to wide change in participation factors without the need to re-tune the controller parameters is also investigated. To update the participation factors to the new values, two conditions are observed. The first one is that the participation factors must not be identical in the two areas and the second one is that the unit with the biggest participation factor must not be the same in the two areas. The updated participation factors for thermal, hydro and wind units in area-1 are changed to $0.3,0.6$, and 0.1 respectively while for thermal, hydro, diesel units in area-2 are assumed $0.7,0.1$, and 0.2 respectively. Then the dynamic performance of the proposed controller under such participation factors variation is tested as shown in Figure 5. It is obvious that the system has a stable performance with no need to re-optimize controller's parameters. 


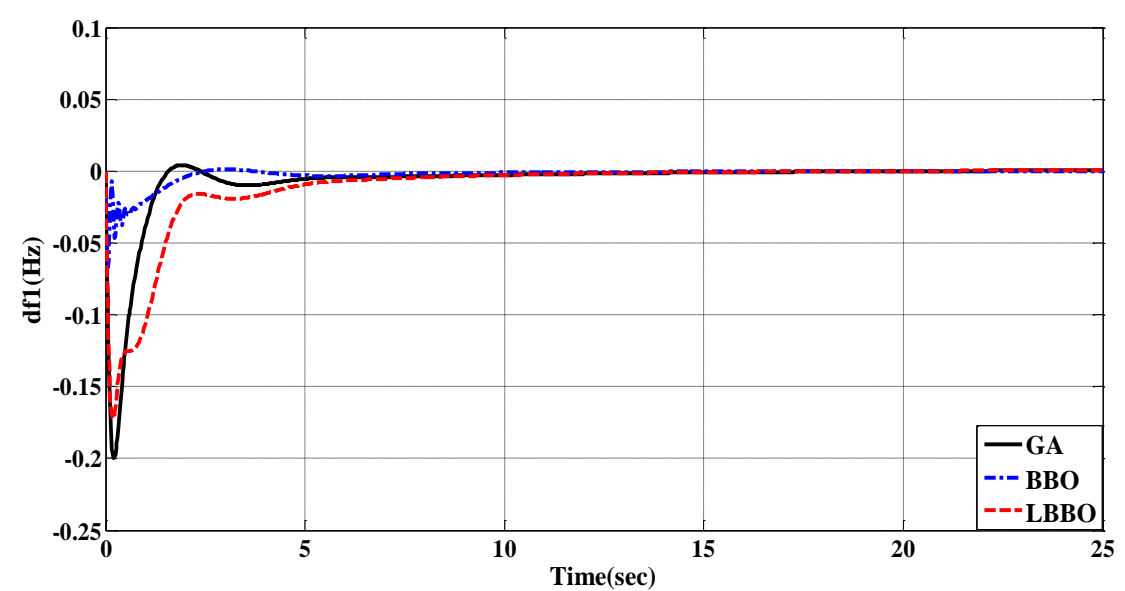

(a)

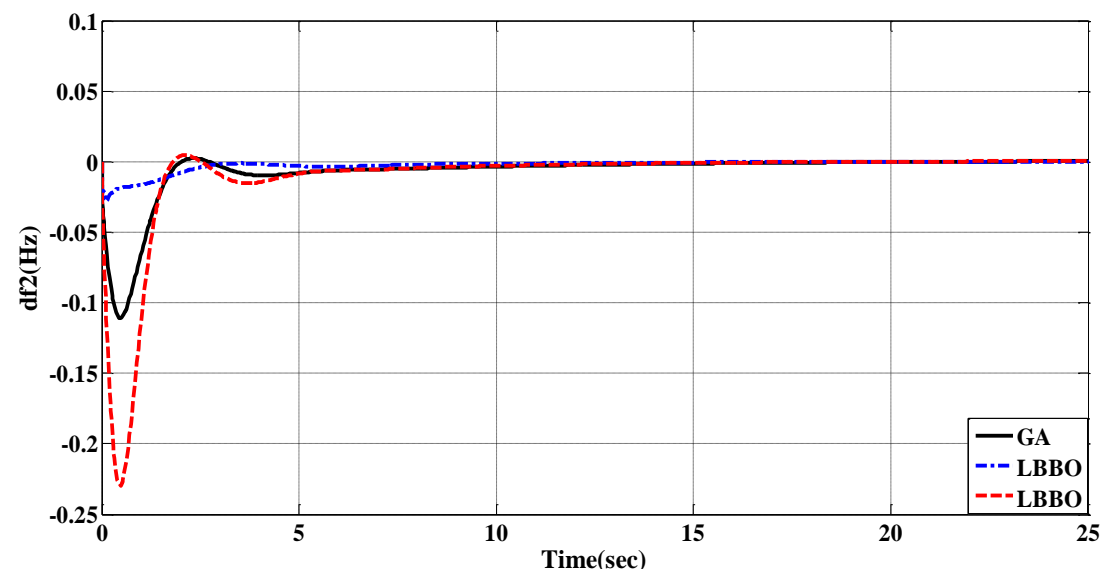

(b)

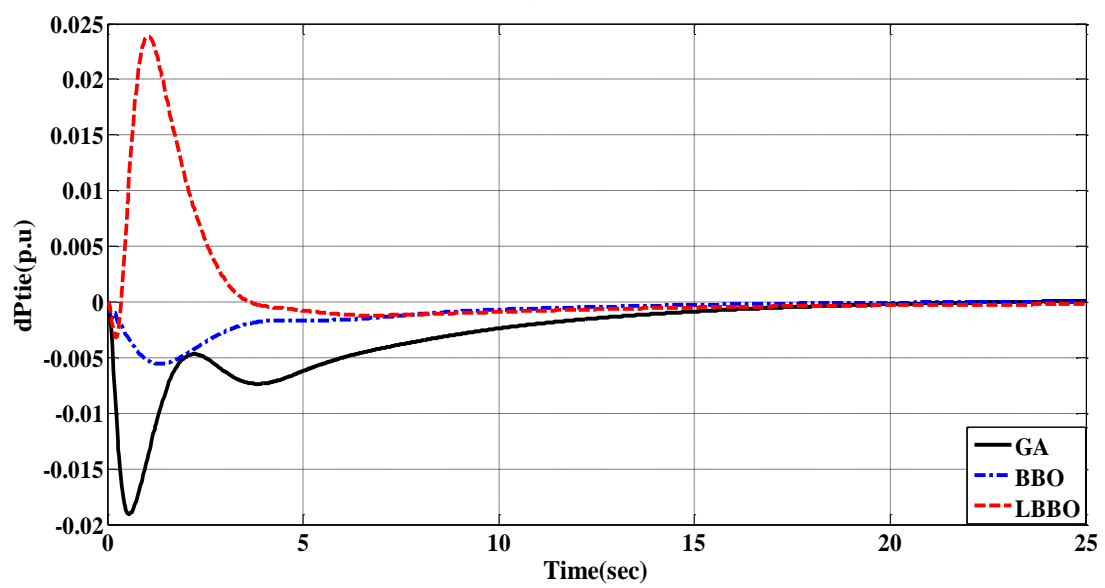

(c)

Figure 4. Test system performance for $30 \%$ step load increase in both areas,

(a) Change in frequency of area-1, (b) Change in frequency of area-2, (c) Change in tie line power

Table 3. Comparative performance for applying 30\% step load increase in both areas

\begin{tabular}{ccccccc}
\hline Controllers & \multicolumn{3}{c}{ Settling time (sec) } & \multicolumn{3}{c}{ Peak overshoot (p.u) } \\
& $\Delta F_{1}$ & $\Delta F_{2}$ & $\Delta P_{\text {tie }}$ & $\Delta F_{1}$ & $\Delta F_{2}$ & $\Delta P_{\text {tie }}$ \\
\hline GA tuned proposed PID-P & 8.34 & 14 & 20.97 & 0.2 & 0.111 \\
BBO tuned proposed PID-P & 9.7 & 16.18 & 20.84 & 0.0673 & 0.0273 & 0.0056 \\
LBBO tuned proposed PID-P & 9.74 & 8.45 & 13.88 & 0.1722 & 0.2295 & 0.0239 \\
\hline
\end{tabular}




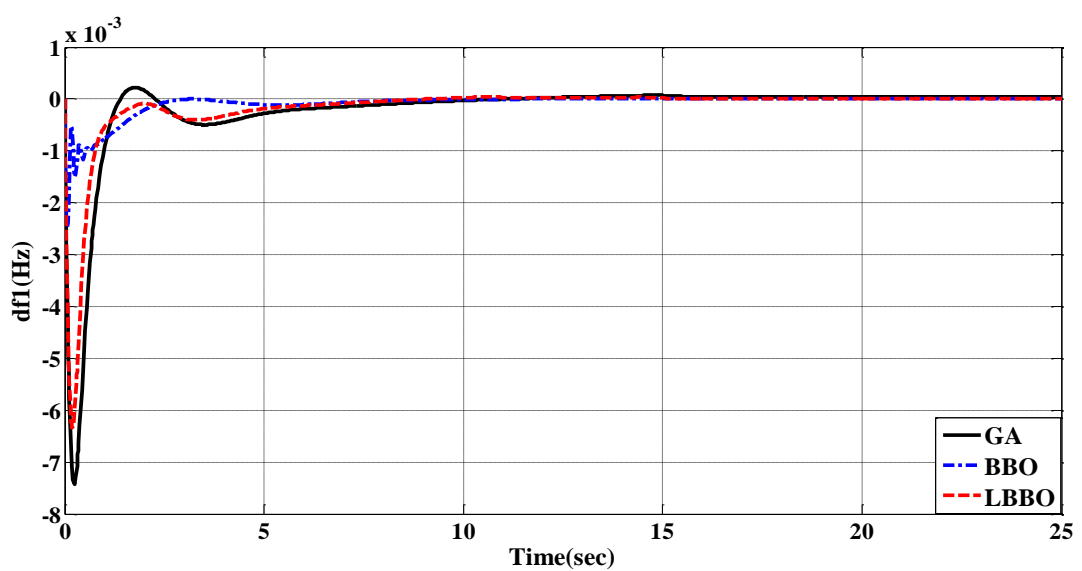

(a)

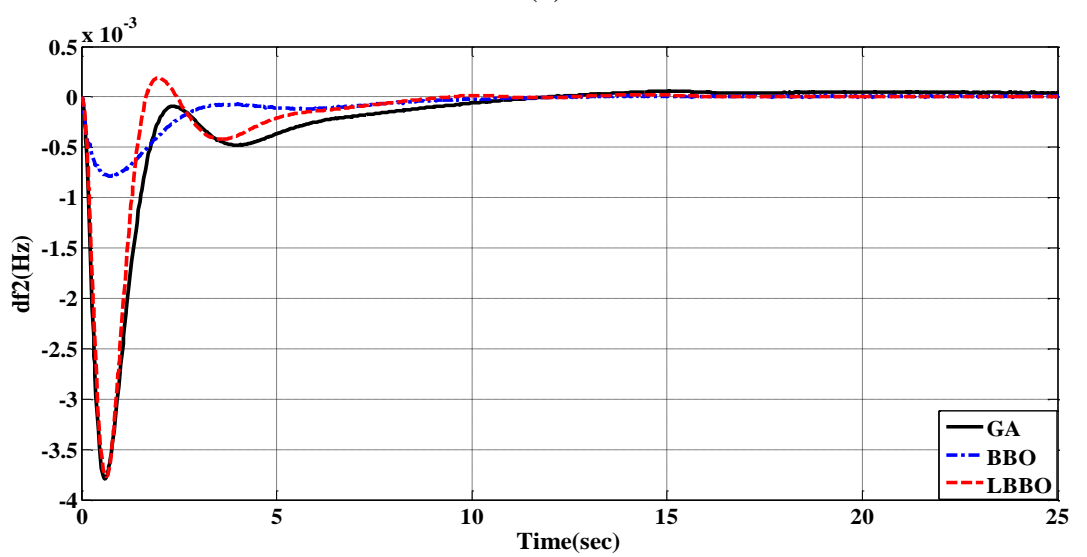

(b)

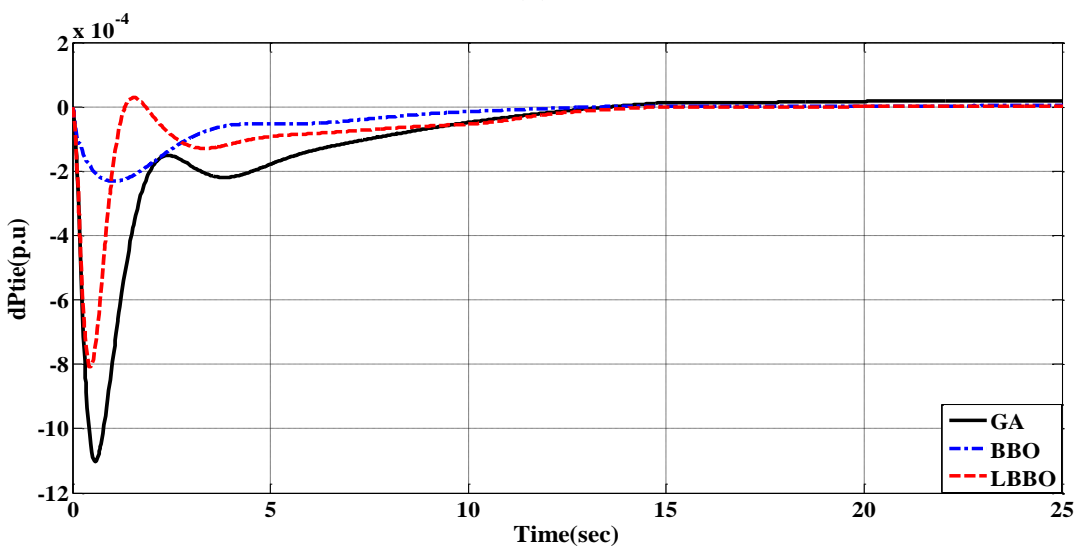

(c)

Figure 5. Test system performance for updated participation factors, (a) Change in frequency of area-1, (b) Change in frequency of area-2, (c) Change in tie line power

\subsection{Fifth Test Procedure: Time Delay}

Due to the growing complexity of power systems, communication delay may be a real challenge for LFC analysis as the time delay can degrade the system's performance and even cause system instability [25]. Meanwhile, a time delay of $0.5 \mathrm{sec}$ is considered in area-1 [25] as it is more suitable for modern communication systems. The updated obtained GA \& LBBO optimized PID-P controller parameters are shown in Table 4, while the dynamic performance of the proposed controllers is illustrated in Figure 6. It is also found that the BBO tuned PID-P controller could not keep up the stability of the system in the presence of this delay time. The inability of BBO to maintain the stability of the system in the presence of time delay may be due to the limitation of BBO as an optimization tool. 
Table 4. Updated optimized parameters of PID-P controller for $0.5 \mathrm{sec}$ delay time

\begin{tabular}{|c|c|c|c|c|c|c|}
\hline & \multicolumn{6}{|c|}{ Controller Parameters of Optimized PID-P for Area-1 } \\
\hline & \multicolumn{2}{|c|}{ Thermal unit } & \multicolumn{2}{|c|}{ Hydro unit } & \multicolumn{2}{|c|}{ Diesel unit } \\
\hline & GA & LBBO & GA & LBBO & GA & LBBO \\
\hline$K_{P 1}$ & 1.008 & 0.102 & 1.5072 & 0.1 & 8.6736 & 0.101 \\
\hline$K_{i}$ & 1.0316 & 0.111 & 23.3141 & 0.246 & 16.5147 & 0.1001 \\
\hline$K_{d}$ & 12.0384 & 0.1005 & 1.2203 & 0.2995 & 4.441 & 0.1007 \\
\hline \multirow[t]{2}{*}{$K_{P 2}$} & 7.9254 & 0.5085 & 2.9489 & 0.2959 & 10.9337 & 0.112 \\
\hline & \multicolumn{6}{|c|}{ Controller Parameters of Optimized PID-P for Area-2 } \\
\hline$K_{P 1}$ & 8.2759 & 0.1002 & 2.9499 & 1.942 & 1.2942 & 0.592 \\
\hline$K_{i}$ & 1.4325 & 0.7604 & 23.1751 & 0.2565 & 6.3013 & 0.138 \\
\hline$K_{d}$ & 19.7879 & 1.0293 & 20.0251 & 0.2681 & 13.0733 & 0.104 \\
\hline$K_{P 2}$ & 15.0634 & 1.1497 & 1.5023 & 0.2989 & 10.7218 & 0.1288 \\
\hline
\end{tabular}

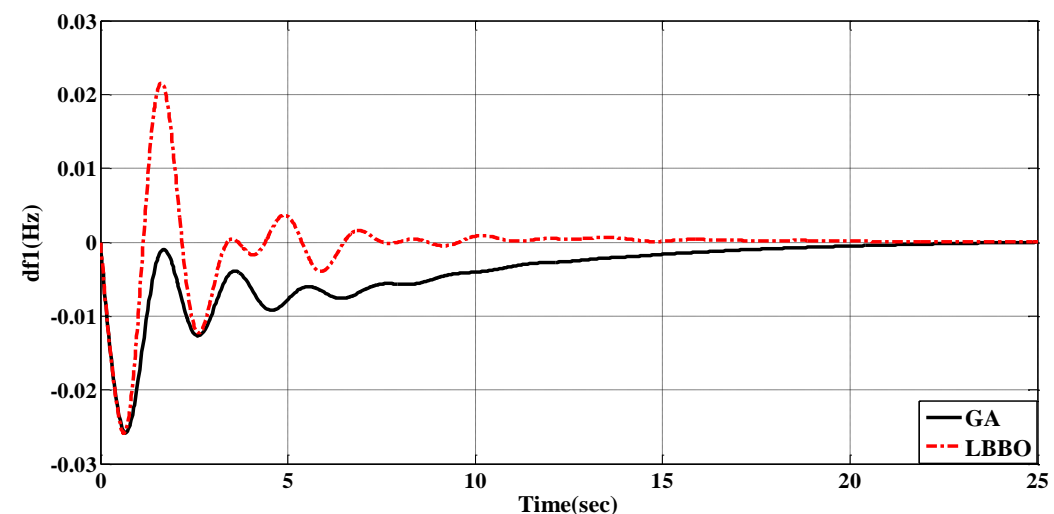

(a)

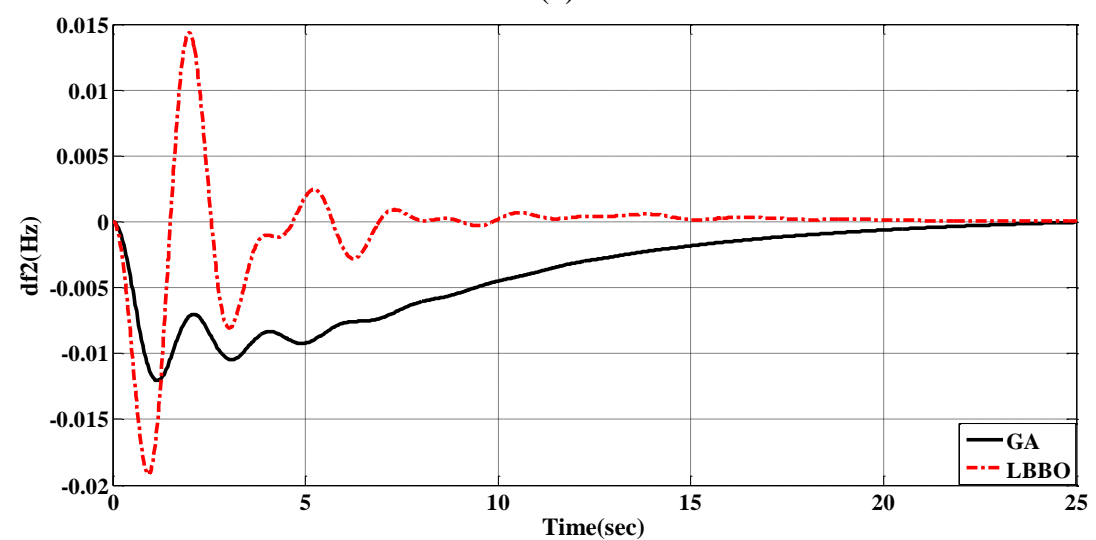

(b)

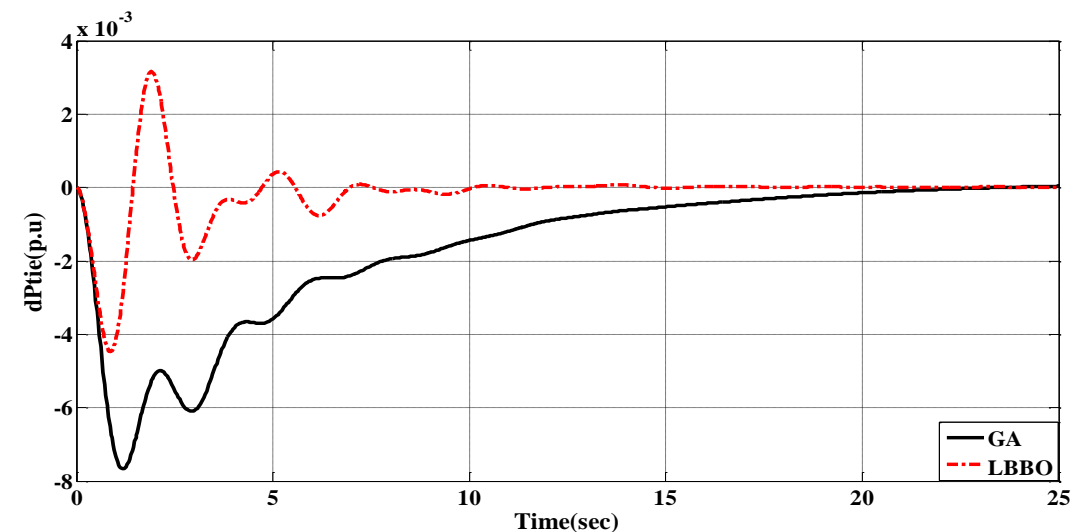

(c)

Figure 6. Test system performance for $0.5 \mathrm{sec}$ delay time, (a) Change in frequency of area-1, (b) Change in frequency of area-2, (c) Change in tie line power 
The comparative analysis in Table 5 shows the ability of both GA tuned PID-P and LBBO tuned PID-P control to maintain the stability of the system in the presence of time delay with acceptable values of settling time and overshoot. It is also clear that the performance of proposed LBBO tuned PID-P control is better as it has lower settling time values rather than GA tuned proposed PID-P.

Table 5. Proposed PID-P performance for applying 0.5 sec delay time

\begin{tabular}{ccccccc}
\hline Controllers & \multicolumn{3}{c}{ Settling time (sec) } & \multicolumn{3}{c}{ Peak overshoot (p.u) } \\
& $\Delta F_{1}$ & $\Delta F_{2}$ & $\Delta P_{\text {tie }}$ & $\Delta F_{1}$ & $\Delta F_{2}$ & $\Delta P_{\text {tie }}$ \\
\hline GA tuned proposed PID-P & 21.43 & 24.85 & 21.38 & 0.0258 & 0.012 & 0.0077 \\
LBBO tuned proposed PID-P & 13.91 & 14.45 & 9.86 & 0.0259 & 0.0192 & 0.0045 \\
\hline
\end{tabular}

\section{CONCLUSION}

In this paper, enhancing LFC of multi-area multi-sources power system including both renewable units and conventional units using a new application of PID-P controller is presented. Such LFC improvement takes into consideration the physical constraints and nonlinearities. The PID-P controller is evaluated for a multi-area multi-source including thermal with reheater, hydro, wind and diesel units. It is deduced that the PID-P controller has the same advantages of the PID controller plus the ability to overcome the PID controller structural limitation in the integration process by converting it to an open loop stable process via the internal feedback loop.

Different test procedures, including wide changes in system parameters, load conditions, participation factors and time delay, are applied to examine LFC enhancement using optimized tuned PID-P controllers. It is clear that, the LBBO tuned PID-P controller achieves significant improvement of $71.87 \%$, $69.2 \%$ and $24.04 \%$ in the settling time for the frequency deviation in area-1, area- 2 and tie line power flow respectively in the presence of 0.01 p.u step load increase in area-1 as compared to DE optimized PIDD controller as a recent published controller for such system. As a future work the performance of the selected controller can be investigated in the presence of FACTS controllers such as TCSC (Thyristor Controlled Series Compensation) and UPFC(Unified Power Flow Controller) also it can be integrated to a hybrid control strategy with artificial intelligence based controllers such as fuzzy ,reinforcement and neural network controllers.

\section{APPENDIX}

$B_{1}=B_{2}=0.425$ p.u MW $/ \mathrm{HZ} ; R_{1}=R_{2}=R_{3}=R_{4}=R_{5}=R_{6}=2.4 \mathrm{~Hz} / \mathrm{p} . u ; T_{g 1}=T_{g 2}=0.08 \mathrm{sec} T_{t 1}=T_{t 2}=$ $0.3 \mathrm{sec} ; a_{12}=-1 ; K_{r 1}=K_{r 2}=0.333 ; T_{r 1}=T_{r 2}=10 \mathrm{sec} ; T_{G H 1}=T_{G H 2}=48.7 \mathrm{sec} ; \mathrm{Kps} 1=K p s=$ $120 \mathrm{~Hz} /$ p.u. $M W ;$ Tps $1=T p s 2=20 \mathrm{sec} ; T_{R S 1}=T_{R S 2}=0.513 \mathrm{sec} ; T_{R H 1}=T_{R H 2}=10 \mathrm{sec} ; T_{W 1}=1 ; K_{\text {diesel }}=$ $16.5 \mathrm{sec} ; K_{p 1}=1.25 ; K_{p 2}=1.4 ; T_{12}=0.0866 \mathrm{p} . u ; T_{p 1}=6 ; T_{p 2}=0.041 ; K_{1}=0.85 ; K_{2}=0.095 ; K_{3}=$ $0.92 ; K_{I B}=0.03 ; T_{I B}=26 ; T_{R B}=6.9 ; C_{B}=200 ; T_{D}=0 ; T_{F}=10$.

\section{REFERENCES}

[1] P. Kundur, "Power system stability and control," New Delhi: McGraw Hill, 2005.

[2] H. S. B. V. e M. E., "A robust PID controller based on imperialist competitive algorithm for load-frequency control of power systems," ISA Transactions, vol. 52, pp. 88-95, 2012.

[3] H. G. M. T. e I. K., "Comparative performance analysis of Artificial Bee Colony algorithm in automatic generation control for interconnected reheat thermal power system," International Journal of Electrical Power and Energy Systems, vol. 42, pp. 167-178, 2012.

[4] S. A.-E. e E. A., "Load frequency controller design via BAT algorithm for nonlinear interconnected power system," International Journal of Electrical Power and Energy Systems, vol. 77, pp. 166-177, 2016.

[5] S. P. e N. K. Y., "Automatic generation control of multi-area power system using multi-objective non-dominated sorting genetic algorithm-II," International Journal of Electrical Power and Energy Systems, vol. 53, pp. 54-63, 2013.

[6] E. Nikmanesh, et al., "Pareto design of Load Frequency Control for interconnected power systems based on multiobjective uniform diversity genetic algorithm (MUGA)," Electrical Power and Energy Systems, vol. 80, pp. 333-346, 2016.

[7] D. K. Chaturvedi, et al., "Load frequency control: a generalized neural network approach," International Journal of Electrical Power and Energy Systems, vol. 21, pp. 405-415, 1999.

[8] H. A. Yousef, et al., "Load Frequency Control of a Multi-Area Power System: An Adaptive Fuzzy Logic Approach,” IEEE Transactions on Power Systems, vol. 29, pp. 1822-1830, 2014. 
[9] T. Mahto and V. Mukherjee, "A novel scaling factor based fuzzy logic controller for frequency control of an isolated hybrid power system," Energy, vol. 130, pp. 339-350, 2017.

[10] A. Nabil, et al., "Linearized Biogeography Based optimization tuned PID-P controller for load frequency control of interconnected power system," em Nineteenth International Middle East Power Systems Conference (MEPCON), Menoufia, Egypt, 2017.

[11] R. K. Sahu, et al., "Design and analysis of hybrid firefly algorithm-pattern search based fuzzy PID controller for LFC of multi area power systems," Electrical Power and Energy Systems, vol. 69, pp. 200-212, 2015.

[12] R. K. S. S. P. e G. C. S., "A novel hybrid PSO-PS optimized fuzzy PI controller for AGC in multi area interconnected power systems," International Journal of Electrical Power and Energy Systems, vol. 64, pp. 880-893, 2015.

[13] P. C. Pradhan, et al., "Firefly algorithm optimized fuzzy PID controller for AGC of multi-area multi-source power systems with UPFC and SMES," Engineering Science and Technology, 2015.

[14] X. Wang, et al., "Dynamic load frequency control for high-penetration wind power considering wind turbine fatigue load," Electrical Power and Energy Systems, vol. 117, 2020.

[15] J. H. Park, et al., "An enhanced PID control strategy for unstable processes," Automatica, vol. 6, pp. 751-756, 1998.

[16] S. W. Sung and I. B. Lee, "Limitations and Countermeasures of PID controllers," Industrial and Engineering Chemistry Research, vol. 35, pp. 2596-2610, 1996.

[17] R. K. Sahu, et al., "Automatic generation control of multi-area power systems with diverse energy sources using Teaching Learning Based Optimization algorithm," Engineering Science and Technology, vol. 19, pp. 113-134, 2015.

[18] B. Mohanty, et al., "Differential evolution algorithm based automatic generation control for interconnected power systems with non-linearity," Alexandria Eng. J., vol. 53, pp. 537-552, 2014.

[19] S. P. Singh, et al., "Analytic hierarchy process based automatic generation control of multi-area interconnected power system using Jaya algorithm," Engineering Applications of Artificial Intelligence, vol. 60, p. 35-44, 2017.

[20] R. K. Sahu, et al., "Teaching learning based optimization algorithm for automatic generation control of power system using 2-DOF PID controller," International Journal of Electrical Power and Energy Systems, vol. 77, pp. 287-301, 2016.

[21] R. More, et al., "Automatic generation control of a multi-area system using ant lion optimizer algorithm based PID plus second order derivative controller," International Journal of Electrical Power and Energy Systems, vol. 80, pp. 52-63, 2016.

[22] R. K. Sahu, et al., "A novel hybrid DEPS optimized fuzzy PI/PID controller for load frequency control of multi-area interconnected power systems," Journal of Process Control, vol. 24, pp. 1596-1608, 2014.

[23] R. K. Sahu, et al., "DE optimized parallel 2-DOF PID controller for load frequency control of power system with governor dead-band nonlinearity," International Journal of Electrical Power and Energy Systems, vol. 49, pp. 19-33, 2013.

[24] R. K. Sahu, et al., "A Novel hybrid gravitational search and pattern search algorithm for load frequency control of nonlinear power system," Applied Soft Computing, vol. 29, pp. 310-327, 2015.

[25] R. K. Sahu, et al., "A novel hybrid PSO-PS optimized fuzzy PI controller for AGC in multi area interconnected power systems," International Journal of Electrical Power and Energy Systems, vol. 64, p. 880-893, 2015. 